\title{
Viabilidade de sementes de jabuticabeira açu em função da condição e período de armazenamento
}

Cristiano Hossel, Américo Wagner Júnior, Jéssica Scarlet Alves De Oliveira Hossel, Kamila Cristina Fabiane, Adriana Dallago, Larissa Corradi Voss

Universidade Tecnológica Federal do Paraná - UTFPR, Agronomia. E-mail: cristianohossel@gmail.com

\section{Resumo}

O objetivo do estudo foi avaliar a viabilidade de sementes de jabuticabeira açu [Plinia cauliflora (DC.) Berg], em função das condições e períodos de armazenamento. O experimento foi na Universidade Tecnológica Federal do Paraná - Câmpus Dois Vizinhos. As sementes foram separadas em lotes, com aquelas mantendo ou retirando a mucilagem. Os lotes foram acondicionados em garrafa $\mathrm{PET}^{\circ}$ ou saco de papel $\mathrm{Kraft}^{\circ} \mathrm{em}$ temperatura ambiente e, saco $\mathrm{Kraft}{ }^{\circ} \mathrm{em} 6{ }^{\circ} \mathrm{C} \pm 1^{\circ} \mathrm{C}$. Testaram-se oito períodos de armazenamento $(0,5,10$, $15,20,25,30$ e 60 dias). Após cada período, as sementes foram semeadas em caixas Gerbox, sem tampa contendo areia grossa e mantidas em B.O.D. a $25{ }^{\circ} \mathrm{C}$ sem fotoperíodo. Usou-se delineamento inteiramente casualizado, em fatorial $2 \times 8 \times 3$ (presença de mucilagem $\times$ período de armazenamento $\times$ condições de armazenamento), com 4 repetições de 50 sementes. As sementes sem mucilagem, em garrafa PET, mantiveram-se viáveis até 30 dias de armazenamento, com valores de $80 \%$ emergência até o décimo quinto dia quando comparados ao uso do papel $\mathrm{Kraft}^{\circ}$. Com mucilagem, em papel $\mathrm{Kraft}^{\circ}$, as sementes mantiveram a viabilidade inalterada até os vinte dias de armazenamento. Deve-se retirar a mucilagem das sementes de jabuticabeira açu, para em seguida armazená-las em garrafa $\mathrm{PET}^{\circ}$ na temperatura ambiente. Estas condições permitem que não haja comprometimento da emergência e do vigor por no máximo 25 dias.

Palavras-chave: Myrtaceae; Plinia cauliflora; emergência.

\section{Seed viability of jabuticaba tree according to the condition and storage period}

\begin{abstract}
The aim of this study was to evaluate the germination viability of jabuticaba açu [Plinia cauliflora (DC.) Berg] seed, according to conditions and the storage time. The experiment was carried out at UTFPR Câmpus Dois Vizinhos, Brazil. The seeds were separated into two groups, with one it remained a mucilage surrounding the seed and without mucilage. The seeds with and without mucilage were put in Pet bottle, paper $\mathrm{Kraft}^{\circ}$ bag at natural condition temperature and paper $\mathrm{Kraft}^{\circ}$ bag in the refrigerator $\left(6^{\circ} \mathrm{C} \pm 1{ }^{\circ} \mathrm{C}\right)$, which it was stored during 8 periods $(0,5,10,15,20,25,30$ and 60 days). After each period, the seeds were sown in Gerbox boxes without lid containing sand as substrate and it taken to BOD at $25{ }^{\circ} \mathrm{C}$ without photoperiod. The experiment was completely randomized in a factorial $2 \times 8 \times 3$ (presence of mucilage $x$ storage period $x$ storage location), with 4 replications of 50 seeds each experimental unit. The seeds without mucilage, in $\mathrm{PET}^{\circ}$ bottle were with viability until 30 days of storage, with $80 \%$ emergence until fifth day to $\mathrm{Kraft}^{\circledR}$ paper. With mucilage, on $\mathrm{Kraft}^{\circledR}$ paper, the seeds kept viability unchanged until twenty days of storage. The mucilage of the jabuticaba açu seeds should be removed and then stored in a PET $^{\circledR}$ bottle at room temperature. These conditions allow no compromise of emergency and vigor for a maximum of 25 days.

Keywords: Myrtaceae; Plinia cauliflora; emergence.
\end{abstract}




\section{Introdução}

A jabuticabeira (Plinia sp.) pertence à família Myrtaceae, sendo fruteira nativa que apresenta distribuição no Centro/Sul/Sudeste do Brasil, sendo conhecidas nove espécies, das quais se destaca Plinia peruviana Berg, conhecida como jabuticabeira de cabinho; Plinia cauliflora (DC) Berg, como jabuticabeira açu ou jabuticabeira paulista, e Plinia jaboticaba (Vell.) Berg, cujo nome denomina-se como jabuticabeira sabará (SASSO et al., 2010a).

Todas as espécies de jabuticabeira apresentam como principal forma de comercialização os frutos, que podem ser consumidos in natura ou industrializados como geleias, sorvetes, sucos, bebidas fermentadas ou licores (DANNER et al., 2011). No entanto, vem sendo descobertas diferentes potencialidades, como a presença do poder antimicrobiano (MACEDO-COSTA et al., 2009) e antimutagênico (SANT'ANA, 2014) das folhas. Dessa forma, acredita-se que em breve essa espécie passará a ser cultivada em maior escala comercial, aumentando-se a demanda por mudas.

A produção de mudas de jabuticabeira tem sido realizada através da multiplicação de plantas pelas técnicas de alporquia (DANNER et al., 2006; SASSO et al., 2010a), enxertia (SASSO et al., 2010a; FRANCO et al., 2010), e pela via seminífera, que ainda prevalece sobre as demais pelas dificuldades encontradas na obtenção de clones, sendo o uso da semente considerada forma mais fácil e rápida de ser utilizada (SASSO et al., 2010b).

Entretanto, as sementes desta espécie são consideradas recalcitrantes, não tolerando a dessecação natural, 0 que dificulta 0 armazenamento das mesmas por longos períodos de tempo em temperatura ambiente (DANNER et al., 2011). Desta forma, tem-se a necessidade de buscar algumas alternativas que promovam a manutenção da viabilidade e maior longevidade das mesmas.

A conservação da viabilidade de sementes recalcitrantes está focada basicamente em mantê-las com alto teor de umidade em baixas temperaturas. $\mathrm{O}$ alto teor de umidade pode influenciar negativamente se as sementes forem mantidas em temperatura ambiente, pois poderá iniciar o processo germinativo durante o armazenamento ou ainda ocorrer a contaminação de fungos, fato que pode comprometer a viabilidade de todas as sementes de um lote (FIOR et al., 2010).
A adoção de baixas temperaturas tem apresentado resultados satisfatórios nas sementes recalcitrantes, pois agem na redução da perda de água e do metabolismo da mesma, economizando-se as reservas, que serão utilizadas posteriormente para o processo de germinação (NEVES et al., 2014).

Entretanto, deve-se ficar atento aos valores mínimos de perda de água toleráveis pelas sementes, pois nas fruteiras nativas com sementes recalcitrantes, a viabilidade é prejudicada quando se atinge teor de água inferior a $45 \%$ e perda total da capacidade germinativa em porcentagem inferior a $15 \%$ (DELGADO; BARBEDO, 2007).

Neste sentido, pode-se aconselhar a junção do uso de temperaturas baixas e de embalagens impermeáveis que permitem a conservação do teor de umidade das sementes. Desta forma, a redução da perda de umidade será influenciada diretamente pela diminuição das trocas gasosas do ambiente com a semente, além da redução das atividades metabólicas, pelo aumento no teor de $\mathrm{CO}_{2}$ dentro da embalagem, o que evitará a germinação da mesma durante o armazenamento.

Outra forma que poder-se-ia testar, seria de realizar a extração da semente mantendo-se a mucilagem aderida, como já testado em maracujazeiro doce (Passiflora alata Curtis) por Ferreira et al. (2005), espécie com sementes recalcitrantes. No entanto, o uso desta técnica pode dificultar o processo germinativo pós-armazenamento, através de maior número de dias para início da germinação como já visto por Rossa et al. (2010), em sementes de jabuticabeira, em curto período de armazenamento. Mas não se sabe o comportamento por maiores períodos de tempo e em diferentes condições de armazenamento, fatos que deverão ser comprovados.

Diante disso, o objetivo foi avaliar a viabilidade de sementes de jabuticabeira açu [Plinia cauliflora (DC.) Berg], de acordo com as condições e períodos de armazenamento.

\section{Material e Métodos}

O experimento foi realizado no Laboratório de Fisiologia Vegetal, da Universidade Tecnológica Federal do Paraná (UTFPR) - Câmpus Dois Vizinhos, em setembro de 2015.

O experimento foi instalado em delineamento inteiramente casualizado, em 
fatorial $2 \times 8 \times 3$ (presença e ausência de mucilagem $x$ período de armazenamento $x$ condições de armazenamento), com 4 repetições de 50 sementes por cada unidade experimental.

Foram utilizadas sementes de jabuticabeira açú [Plinia cauliflora (DC.) Berg] obtidas de frutos maduros (coloração do epicarpo atropurpúrea) (ALEXANDRE et al., 2006). Para a extração das sementes foi realizado o amassamento manual dos frutos contra superfície plana e firme de bancada, de modo que estourassem e expusessem suas sementes.

Posteriormente, separou-as em dois lotes, de forma que em um manteve-se a mucilagem de revestimento da semente, secando-as a sombra durante 72 horas e em outro, tal mucilagem foi retirada manualmente, por meio de friç̧ão em peneira de malha fina, acrescentando-se cal virgem. Após a remoção da mucilagem, as sementes foram lavadas em água corrente e dispostas em papel toalha, onde permaneceram durante 24 horas à sombra para retirada do excesso de umidade.

Em seguida as sementes com e sem mucilagem foram pesadas e separadas em três sub-lotes, dois quais foram distribuídas de acordo com as condições de armazenamento sendo estas, garrafa $\mathrm{PET}^{\circ}$ em temperatura ambiente, saco de papel Kraft ${ }^{\circ}$ em temperatura ambiente e saco de papel Kraft em geladeira $\left(6^{\circ} \mathrm{C} \pm 1^{\circ} \mathrm{C}\right)$.

Após cada período de armazenamento $(0,5,10,15,20,25,30$ e 60 dias), as sementes foram pesadas novamente e semeadas em caixas Gerbox, sem tampa contendo como substrato areia grossa. Em seguida, foram levadas para B.O.D. a $25^{\circ} \mathrm{C}$ sem fotoperíodo (PICOLOTTO et al., 2007). A finalidade de nova pesagem foi para obter a perda de umidade durante cada período em que ficaram armazenadas. Procedeu-se diariamente com a conferência da umidade do substrato e quando necessário acrescentou-se água destilada.

Foram analisadas as porcentagens de emergência, o índice de velocidade de emergência das mesmas (IVE) (do décimo quarto dia até o centésimo dia) (MAGUIRE, 1962) e a perda de umidade através da diferença ocorrida entre as pesagens no início e final do armazenamento.

Os dados das variáveis avaliadas foram previamente submetidos ao teste de normalidade de Lilliefors, constando-se a necessidade da transformação para emergência e IVE, efetuadas por meio do arco-seno raiz de $x / 100$ e raiz quadrada de $x+1$, respectivamente. Com a transformação dos dados, os mesmos foram submetidos à análise de variância e ao teste de Duncan $(\alpha=0,05)$ para o fator qualitativo e de regressão $(p \leq 0,05)$ para o fator quantitativo, com uso do programa Genes (CRUZ, 2001).

\section{Resultados e Discussão}

Através dos resultados obtidos verificou-se interação significativa entre 'presença e ausência de mucilagem $x$ local de armazenamento' para 0 percentual de emergência (Tabela 1). Na Tabela 1, verificou-se que, quando as sementes de jabuticabeira foram armazenadas com a presença de mucilagem, diferenciaram-se estatisticamente, apresentando maiores porcentagens de emergência de plântulas quando armazenadas em sacos de papel em geladeira $\left(6^{\circ} \mathrm{C}\right)$. Quando as sementes foram armazenadas sem a presença de mucilagem a garrafa PETPET $^{\oplus}$ foi a que diferiu estatisticamente, apresentando maior porcentagem de emergência de plântulas. Também foi possível verificar que em todas as embalagens de armazenamento, a porcentagem de emergência de plântulas foi superior quando armazenadas sem mucilagem.

Com a mucilagem percebeu-se menor emergência, o que pode estar relacionado ao fato de alguma substância química presente que possa estar retardando o início do processo germinativo e não necessariamente a perda de viabilidade, conforme observado por Rossa et al. (2010) com sementes de jabuticabeira em tratamentos pré-germinativos. 
Tabela 1. Emergência (\%) de plântulas de jabuticabeira açu (Plinia cauliflora) em diferentes condições de armazenamento sob a presença ou não da mucilagem. Dois Vizinhos, 2015.

\begin{tabular}{cccc}
\hline \multirow{2}{*}{$\begin{array}{c}\text { Presença de } \\
\text { Mucilagem }\end{array}$} & $\begin{array}{c}\text { Garrafa PET } \\
\text { /temperatura } \\
\text { ambiente }\left(25^{\circ} \mathrm{C}\right)\end{array}$ & $\begin{array}{c}\text { Condições de armazenamento } \\
\text { papel/temperatura } \\
\text { ambiente }\left(25^{\circ} \mathrm{C}\right)\end{array}$ & $\begin{array}{c}\text { Saco de } \\
\text { papel/geladeira }\left(6^{\circ} \mathrm{C}\right)\end{array}$ \\
\hline Com & $1,77 \mathrm{~b} \mathrm{~B}^{*}$ & $1,75 \mathrm{~b} \mathrm{~B}$ & $5,64 \mathrm{a} \mathrm{B}$ \\
Sem & $26,63 \mathrm{a} \mathrm{A}$ & $8,83 \mathrm{c} \mathrm{A}$ & $15,36 \mathrm{~b} \mathrm{~A}$ \\
\hline $\mathrm{CV}(\%)$ & & 40,41 & \\
\hline
\end{tabular}

*Médias seguidas pela mesma letra minúscula na linha e maiúscula na coluna não diferem entre si, pelo teste Duncan $(p \leq 0,05)$.

Houve interação significativa entre 'presença e ausência de mucilagem $x$ período de armazenamento $x$ condições de armazenamento' para o percentual de emergência (Figura 1). As sementes sem mucilagem, que foram mantidas em garrafa $\mathrm{PET}^{\circ}$ mantiveram-se viáveis até 30 dias de armazenamento, com valores considerados ideais (80\% emergência) até o décimo quinto dia quando comparados a outras embalagens (Kraft ${ }^{\circ}$. As sementes que permaneceram com a presença da mucilagem, que foram armazenadas em papel $\mathrm{Kraft}^{\circ}$ mantiveram a viabilidade inalterada até os vinte dias de armazenamento, conseguindo serem viáveis por até 30 dias, além de se manter superior as demais embalagens dos dez aos vinte dias de armazenamento (Figura 1).
As diferenças entre as médias obtidas com ou sem mucilagem de acordo com a embalagem, pode dizer respeito a característica que cada uma apresenta quanto a capacidade de permitir maior ou menor perda de umidade. Acredita-se que a retirada da mucilagem e uso da garrafa $\mathrm{PET}^{\circ}$ foi favorável porque tal embalagem reduz as trocas entre o ambiente interno e externo associado a mucilagem que pode fazer com que haja fermentação ou contaminação fúngica. Com o papel Kraft as trocas são mais facilitadas. Com isso, neste papel, a mucilagem foi determinante para evitar a perda de umidade da semente para o ambiente externo, favorecendo para mantença da maior viabilidade. 
Figura 1. Emergência (\%) das plântulas de jabuticabeira açu (Plinia cauliflora) de sementes armazenadas nas condições de armazenamento Garrafa PET $/$ Temperatura Ambiente $\left(25^{\circ} \mathrm{C}\right)$ (A), Saco de papel/temperatura ambiente $\left(25^{\circ} \mathrm{C}\right)(\mathrm{B})$ e Saco de papel/geladeira $\left(6^{\circ} \mathrm{C}\right)(\mathrm{C})$ sob diferentes períodos, de acordo com a presença ou não da mucilagem. Dois Vizinhos, 2015.
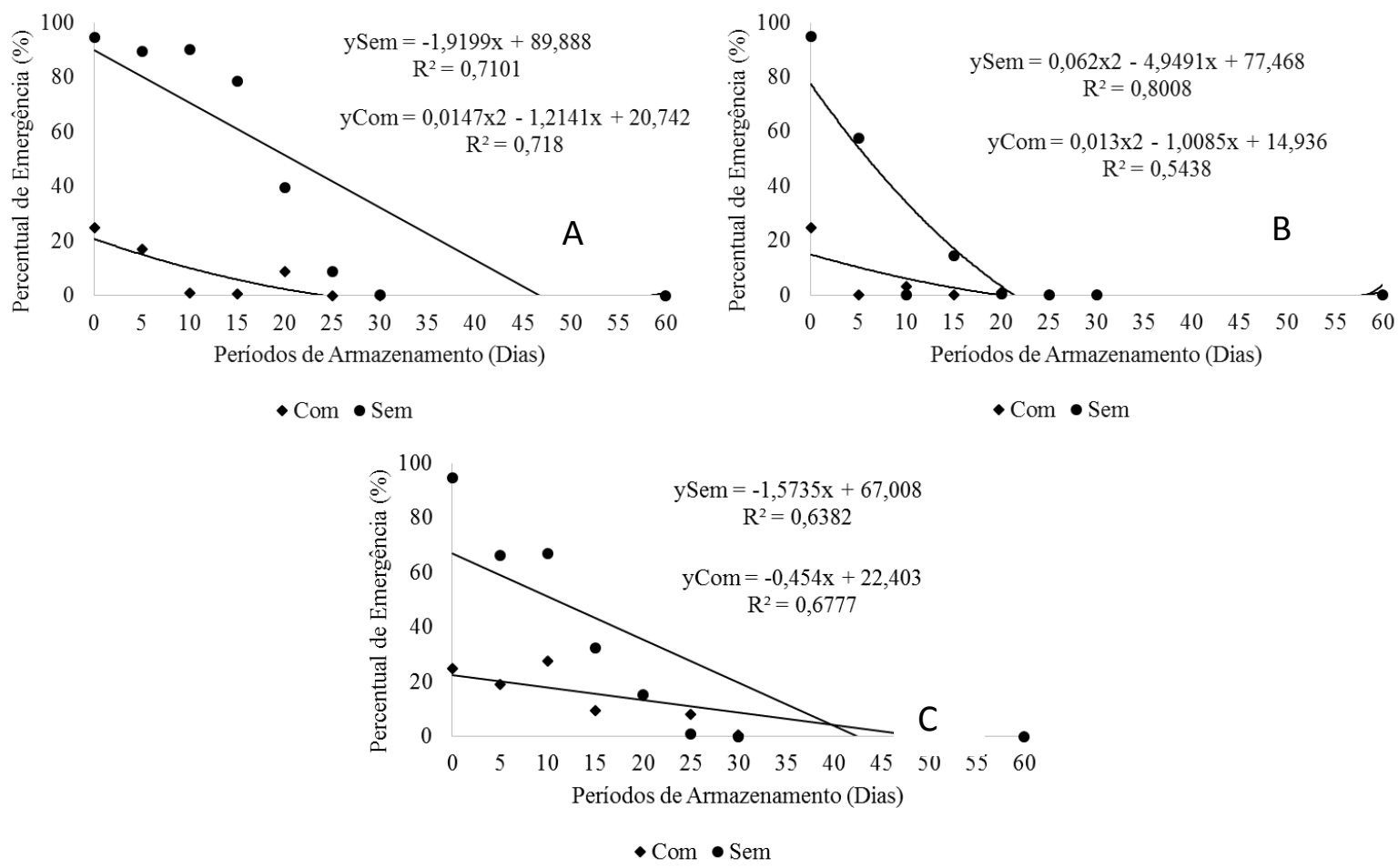

O uso da geladeira para o armazenamento apresentou-se promissor e superior a temperatura ambiente. Resultados semelhantes foram encontrados por Brasileiro et al. (2011) em sementes de nêspera (Eriobotrya japonica Lindl.), que também é caracterizada como recalcitrante.

Vieira et al. (2008) com sementes de camboatã (Cupania vernalis Cambess.) observaram que a redução da temperatura de 25 ${ }^{\circ} \mathrm{C}$ para $10{ }^{\circ} \mathrm{C}$ influenciaram diretamente para maior conservação da viabilidade das sementes, tendo com 240 dias emergência superior a $80 \%$.

Quando comparados de forma direta, o percentual de emergência das plântulas de jabuticabeira com a presença ou ausência da mucilagem permitiu observar que sem o seu uso, a superioridade manteve-se até os vinte dias quando armazenadas em papel Kraft ${ }^{\circ}$, tanto em temperatura ambiente como em geladeira. Com a garrafa $\mathrm{PET}^{\circ}, \mathrm{O}$ armazenamento das sementes sem mucilagem manteve a emergência superior até os vinte cinco dias. Também verificou-se que quando as sementes foram mantidas em geladeira $\quad\left(6^{\circ} \mathrm{C}\right)$ estas apesentaram comportamento linear decrescente do percentual de emergência das plântulas, diferentemente da temperatura ambiente, em que houve ligeira queda de viabilidade das mesmas (Figura 1).

Ferreira et al. (2005) em sementes de maracujazeiro doce ( $P$. alata) tiveram resultados semelhantes, sendo verificado nas armazenadas com arilo, emergência inferior, pelo fato da presença do arilo dificultar a germinação das sementes e mantê-las como latentes.

Obteve-se também interação significativa entre 'presença de mucilagem $\mathrm{x}$ local de armazenamento' para IVE (Tabela 2). Com o IVE, os resultados estatísticos foram semelhantes aos obtidos para emergência de plântulas, quando as sementes foram armazenadas sem mucilagem, de forma que a garrafa $\mathrm{PET}^{\circ}$ permitiu maior vigor até 25 dias de armazenamento, caindo drasticamente seu índice de velocidade de emergência aos 5 dias em papel Kraft ${ }^{\circ}$. Pode-se observar semelhança quando estas foram mantidas em garrafa $\mathrm{PET}^{\circ}$ em geladeira e em papel $\mathrm{Kraft}^{\circ}$ em temperatura ambiente. No entanto, quando estas foram armazenadas em papel $\mathrm{Kraft}^{\circ}$ em geladeira, o IVE foi mantido inalterado até aos 10 dias, diferentemente da emergência que foi até os 20 dias (Figura 2). 
Tabela 2. Índice de velocidade de emergência (IVE) de plântulas de jabuticabeira açu (Plinia cauliflora) obtidas de sementes armazenadas em diferentes condições de armazenamento sob a presença ou não da mucilagem. Dois Vizinhos, 2015.

\begin{tabular}{cccc}
\hline \multirow{2}{*}{$\begin{array}{c}\text { Presença de } \\
\text { Mucilagem }\end{array}$} & $\begin{array}{c}\text { Garrafa PET } \\
\text { /temperatura } \\
\text { ambiente }\left(25^{\circ} \mathrm{C}\right)\end{array}$ & $\begin{array}{c}\text { Condições de armazenamento } \\
\text { papel/temperatura } \\
\text { ambiente }\left(25^{\circ} \mathrm{C}\right)\end{array}$ & $\begin{array}{c}\text { Saco de } \\
\text { papel/geladeira }\left(6^{\circ} \mathrm{C}\right)\end{array}$ \\
\hline Com & $0,07 \mathrm{~b} \mathrm{~B}^{*}$ & $0,06 \mathrm{~b} \mathrm{~B}$ & $0,11 \mathrm{a} \mathrm{B}$ \\
Sem & $0,52 \mathrm{a} \mathrm{A}$ & $0,26 \mathrm{c} \mathrm{A}$ & $0,38 \mathrm{~b} \mathrm{~A}$ \\
\hline CV (\%) & & 4,18 & \\
\hline
\end{tabular}

*Médias seguidas pela mesma letra minúscula na linha e maiúscula na coluna não diferem entre si, pelo teste Duncan $(p \leq 0,05)$.

Figura 2. Índice de velocidade de emergência (IVE) de plântulas de jabuticabeira açu (Plinia cauliflora) obtidas de sementes armazenadas nas condições de armazenamento Garrafa PET /Temperatura Ambiente $\left(25^{\circ} \mathrm{C}\right)(\mathrm{A})$, Saco de papel/temperatura ambiente $\left(25^{\circ} \mathrm{C}\right)$ (B) e Saco de papel/geladeira $\left(6^{\circ} \mathrm{C}\right)$ (C) sob diferentes períodos, de acordo com a presença ou não da mucilagem. Dois Vizinhos, 2015.
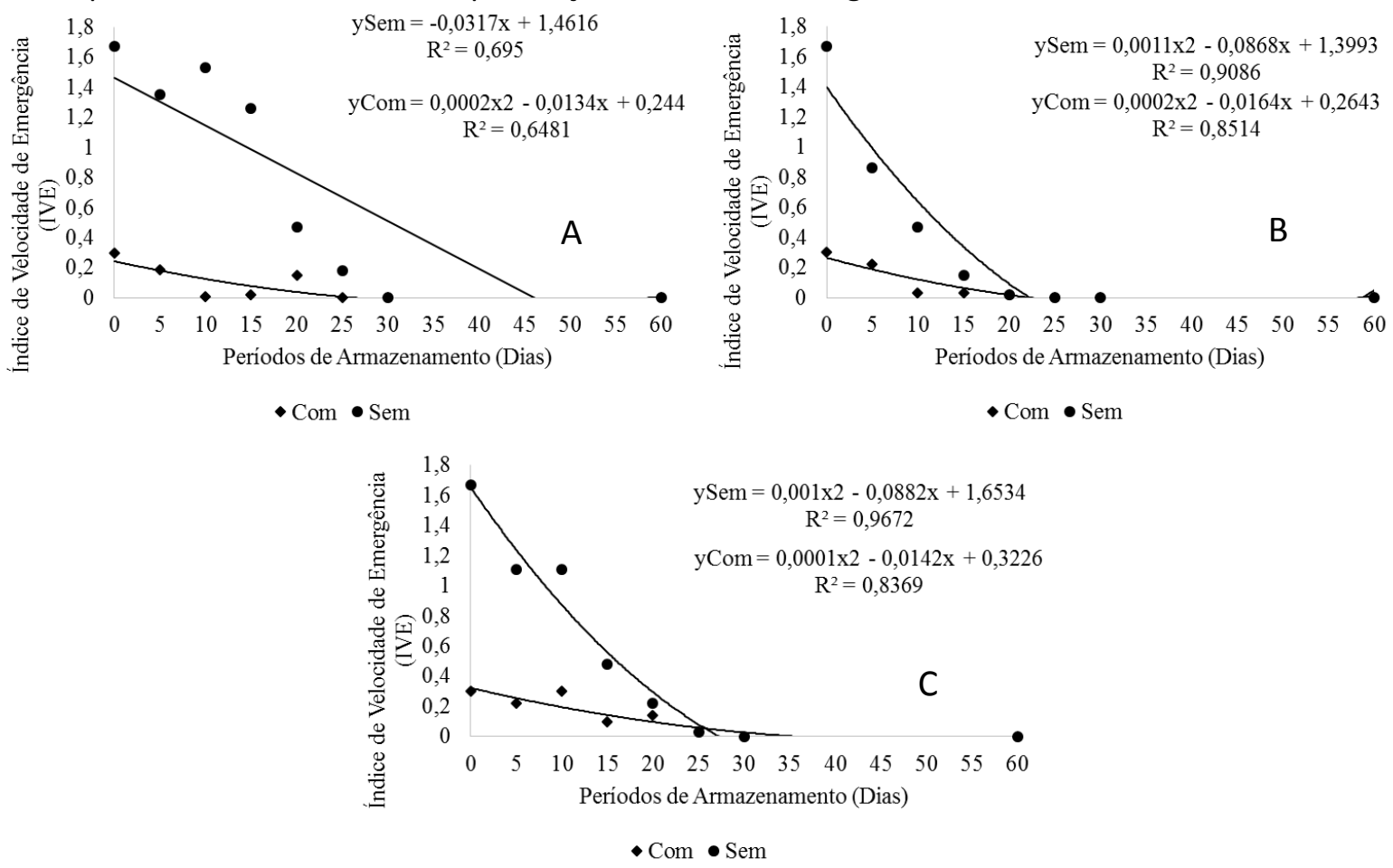

$O$ resultado obtido em geladeira $\left(6^{\circ} \mathrm{C}\right)$ pode estar associado com a menor perda de água e a menor atividade metabólica das sementes, fazendo com que a semente mantivesse maior teor de umidade, importante nas recalcitrantes, além da possibilidade da maior conservação de reserva necessárias para sobrevivência da semente durante o armazenamento e posterior vigor desta com a germinação, conforme constatado pelo IVE (Figura 2).

A superioridade atingida com a garrafa $\mathrm{PET}^{\circ}$ pode estar associada as menores trocas de vapor de água que esta embalagem proporciona durante o armazenamento da semente. Além disto, esta embalagem altera a relação $\mathrm{CO}_{2}: \mathrm{O}_{2}$, aumentando-a de forma que haja redução no metabolismo da semente sem a perda de viabilidade. Isto também foi comprovado por Pirola (2013), que ao utilizar garrafas $\mathrm{PET}^{\circ}$ com tampa e temperaturas controladas $\left(6^{\circ} \mathrm{C}\right)$ no armazenamento de sementes de cerejeira-damata (Eugenia involucrata), outra espécie recalcitrante, obteve aumento no período de viabilidade destas por até 45 dias.

Quando as sementes foram armazenadas sem mucilagem, o uso da garrafa $\mathrm{PET}^{\circ}$ proporcionou menor perda de umidade, de forma que está embalagem e o papel $\mathrm{Kraft}^{\circ} \mathrm{em}$ 
temperatura ambiente apresentaram aumento da perda de umidade de forma linear com $10,31 \%$ e $40,59 \%$ aos 60 dias de armazenamento, respectivamente. Quando as sementes foram armazenadas em papel $\mathrm{Kraft}^{\oplus}$ em geladeira a perda de umidade foi superior, apresentando o ponto máximo de perda aos 42 dias de armazenamento com 33,24\% (Figura 3A).

Como nos resultados encontrados sem a presença de mucilagem, com a mucilagem, o uso da garrafa PET $^{\oplus}$ apresentou menores perdas, sendo esta linear com 7,56\% aos 60 dias de armazenamento. Naquelas armazenadas em papel $\mathrm{Kraft}^{\oplus}$, as perdas de teor de água foram bem maiores. Em temperatura ambiente $\left(25^{\circ} \mathrm{C}\right)$, a perda foi linear com $77,81 \%$ aos 60 dias de armazenamento e em geladeira $\left(6{ }^{\circ} \mathrm{C}\right)$ ocorreu maior redução aos 45 dias com 88,21\% (Figura 3B).

Figura 3. Perda de umidade (\%) das sementes de jabuticabeira ( $P$. cauliflora) sem mucilagem (A) e com mucilagem (B) em função dos períodos de armazenamento (Dias), de acordo com o local de armazenamento (Garrafa PET $^{\circ}$; Papel Kraft ${ }^{\circ}$ em geladeira; Papel Kraft ${ }^{\circ}$ em temperatura ambiente. Dois Vizinhos, 2015.

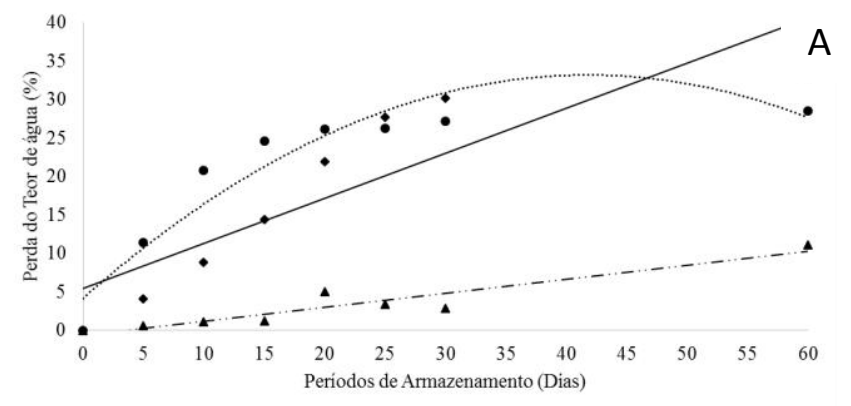

yGarrafa Pet $=0,1818 \mathrm{x}-0,5968$
$\mathrm{R}^{2}=0,888$

Garcia et al. (2014) armazenando sementes de Araucaria angustifolia em refrigerador $\left(5{ }^{\circ} \mathrm{C}\right)$ e embalagens de plásticas transparentes com espessura de 0,015 $\mu \mathrm{m}$, conseguiram manter a viabilidade acima de $64 \%$ por até 180 dias, com grau de umidade praticamente inalterado, considerando-se que as sementes desta espécie também são classificadas como recalcitrantes. Isto ocorre em embalagens impermeáveis, devido haver a criação de microclima no interior da embalagem, não permitindo que ocorra trocas gasosas com o ambiente externo, além de não permitir alteração na umidade pelo contato entre as diferenças de potencial hídrico dos meios.

Leonhardt et al. (2010) avaliando o armazenamento de sementes de Myrcia glabra e M. palustres em câmara fria $\left(5{ }^{\circ} \mathrm{C}\right)$ em embalagem de polietileno, verificaram a manutenção da viabilidade por até cinco e seis meses, respectivamente.

Em geral, a mucilagem apesar de ser barreira física importante para proteção das sementes e muitas vezes atrativa para o consumo

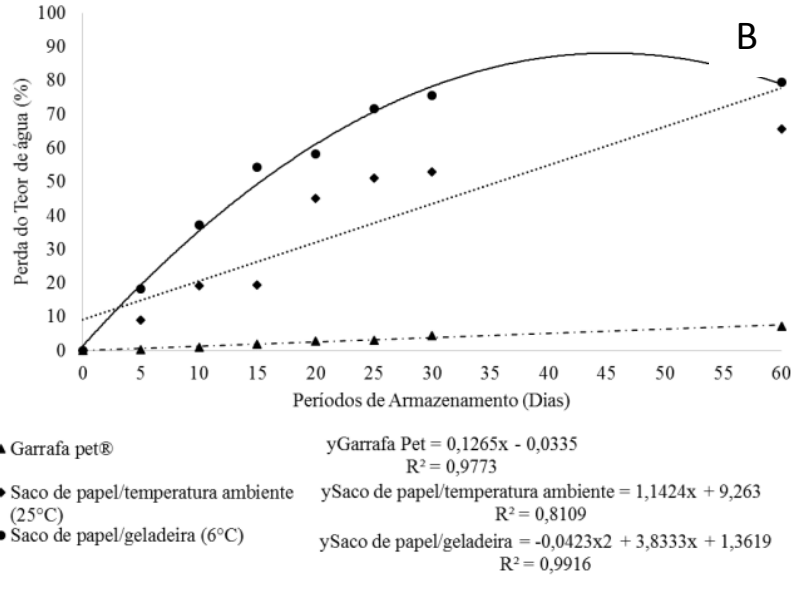

dos dispersores de sementes, quando relacionadas a mantença da viabilidade do poder germinativo das sementes de jabuticabeiras açu não apresentam mesmo efeito positivo, devendose retirá-las previamente ao armazenamento em garrafa $\mathrm{PET}^{\oplus}$ mantidas em temperatura ambiente por até 25 dias.

\section{Conclusões}

Recomenda-se a retirada da mucilagem para posterior armazenamento das sementes de jabuticabeira açu em garrafa PETPET ${ }^{\circ}$, mantendoas em temperatura ambiente no máximo por 25 dias, sem que haja comprometimento da emergência e do vigor.

\section{Referências}

ALEXANDRE, R.S.; WAGNER JÚNIOR, A.; NEGREIROS, J.R.S.; BRUCKNER, C.H. Estádio de maturação dos frutos e substratos na germinação de sementes e desenvolvimento inicial de plântulas de jabuticabeira. Revista Brasileira de Agrociência, v.12, n.2, p.229-232, 2006. 
BRASILEIRO, B. G.; SILVA, D. F. P; BHERING, M. C.; MOURA, E. B. B.; BRUCKNER, C. H. Qualidade fisiológica de sementes de nêspera armazenadas em diferentes embalagens. Revista Brasileira de Fruticultura, v.(esp.), p.686-691, 2011. https://doi.org/10.1590/S010029452011000500096

CRUZ, C. D. Programa genes: aplicativo computacional em genética e melhoramento. 2 . ed. Viçosa: UFV. 2001. 648p.

DANNER, M. A.; CITADIN, I.; FERNANDES JUNIOR, A. A.; ASSMANN, A. P.; MAZARO, S. M.; DONAZZOLO, J. Enraizamento de jabuticabeira (Plinia trunciflora) por mergulhia aérea. Revista Brasileira de Fruticultura, v.28, n.3, p.530-532, $2006 . \quad$ https://doi.org/10.1590/5010029452006000300043

DANNER, M. A.; CITADIN, I.; SASSO, S. A. Z.; AMBROSIO, R.; WAGNER JÚNIOR, A. Armazenamento a vácuo prolonga a viabilidade de sementes de jabuticabeira. Revista Brasileira de Fruticultura, v.33, n.1, p.246-252, 2011. https://doi.org/10.1590/S0100-

$\underline{29452011005000037}$

DELGADO, L. F.; BARBEDO, C. J. Tolerância à dessecação de sementes de espécies de Eugenia. Pesquisa Agropecuária Brasileira, v.42, n.2, p.265-272, 2007. https://doi.org/10.1590/S0100$\underline{204 \times 2007000200016}$

FERREIRA, G.; OLIVEIRA, A.; RODRIGUES, J. D.; DIAS, G. B.; DETONI, A. M.; TESSER, S. M.; ANTUNES, A. M. Efeito de arilo na germinação de sementes de Passiflora alata Curtis em diferentes substratos e submetidas a tratamentos com giberelina. Revista Brasileira de Fruticultura, v.27, n.2, p.277-280, 2005. https://doi.org/10.1590/S0100-

29452005000200022

FIOR, C. S.; RODRIGUES, L. R.; CALIL, A. C.; LEONHARDT, C.; SOUZA, L. S.; SILVA, V. S. Qualidade fisiológica de sementes de guabijuzeiro (Myrcianthes pungens (Berg) Legrand - Myrtaceae) em armazenamento. Revista Árvore, v.34, n.3, p.435-442, 2010. https://doi.org/10.1590/S0100$\underline{67622010000300007}$
FRANCO, L. R. L.; SILVA, J. F.; MAIA, V. M.; LOPES, P. S.; AMORIM, I. J. F.; MIZOBUTSI, E. H. Pegamento e crescimento inicial de mudas de jabuticabeiras 'Açu' e 'Sabará' submetidas a dois tipos de enxertia. Revista Ceres, v.57, n.4, p.535538, 2010. https://doi.org/10.1590/S0034737X2010000400016

GARCIA, C.; COELHO, C. M. M.; MARASCHIN, M.; OLIVEIRA, L. M. Conservação da viabilidade e vigor de sementes de Araucaria angustifólia (Bertol.) Kuntze durante 0 armazenamento. Ciência Florestal, v.24, n.4, p.857-867, 2014. http://dx.doi.org/10.5902/1980509816586

LEONHARDT, C.; CALIL, A. C.; FIOR, C. S. Germinação de sementes de Myrcia glabra (O. Berg) D. Legrand e Myrcia palustris DC. Myrtaceae armazenadas em câmara fria. IHERINGIA, Série Botânica, v.65, n.1, p.25-33, 2010.

MACEDO-COSTA, M. R.; DINIZ, D. N.; CARVALHO, C. M.; PEREIRA, M. S. V.; PEREIRA, J. V.; HIGINO, J. S. Eficácia do extrato de Myrciaria cauliflora (Mart.) O. Berg. (jabuticabeira) sobre bactérias orais. Revista Brasileira de Farmacognosia, v.19, n.2B, p.565-571, 2009.

https://doi.org/10.1590/S0102$\underline{695 \times 2009000400010}$

MAGUIRE, J. D. Speed of germination-aid in selection and evaluation for seedling emergence and vigor. Crop Science, v.2, n.2, p.176-177, 1962.

https://doi.org/10.2135/cropsci1962.0011183X0 $00200020033 x$

NEVES, G.; SERIGATTO, E. M.; DALCHIAVON, F. C.; SILVA, C. A. Viabilidade e longevidade de sementes de Tabebuia aurea Benth. \& Hook. Submetidas a diferentes métodos de armazenamento. Bioscience Journal, v.30, n.3, p.737-742, 2014.

PICOLOTTO, L.; SCHUCH, M. W.; SOUZA, J. A.; SILVA, L. C.; FERRI, J.; FACHINELLO, J. C. Efeito do hipoclorito de sódio, fotoperíodo e temperatura no estabelecimento in vitro de jabuticabeira. Scientia Agraria, v.8, p.19-23, 2007. https://doi.org/10.5380/rsa.v8i1.8337

PIROLA, K. Caracterização fisiológica e conservação de sementes de oito fruteiras 
nativas do bioma floresta com araucária. 2013. 129f. (Dissertação de Mestrado) - Universidade Tecnológica Federal do Paraná, Pato Branco, 2013.

ROSSA, U. B.; TRICHES, G. P.; GROSSI, F.; NOGUEIRA, A. C.; REISSMANN, C. B.; RAMOS, M. R. Germinação de sementes e qualidade de mudas de Plinia trunciflora (Jabuticabeira) em função de diferentes tratamentos prégerminativos. Floresta, v.40, n.2, p.371-378, 2010. http://dx.doi.org/10.5380/rf.v40i2.17832

SANT'ANA, M. R. Avaliação do potencial antiinflamatório e antioxidante da casca da jabuticaba (Myrciaria cauliflora), do açaí jussara (Euterpe edulis Martius) e do jambolão (Syzygium cumini) em camundongos submetidos à dieta de cafeteria. 2014. 44f. (Dissertação de Mestrado) - Universidade Federal Do Espírito Santo, Alegre, Brasil.

SASSO, S. A. Z.; CITADIN, I.; DANNER, M. A. Propagação de jabuticabeira por enxertia e alporquia. Revista Brasileira de Fruticultura, v.32, n.2, p.571-576, 2010a. https://doi.org/10.1590/S0100$\underline{29452010005000055}$

SASSO, S. A. Z.; CITADIN, I.; DANNER, M. A. Propagação de jabuticabeira por estaquia. Revista Brasileira de Fruticultura, v.32, n.2, p.577-583, 2010b. https://doi.org/10.1590/S0100$\underline{29452010005000054}$

VIEIRA, C. V.; ALVARENGA, A. A.; CASTRO, E. M.; NERY, F. C.; SANTOS, M. O. Germinação e armazenamento de sementes de camboatã (Cupania vernalis Cambess.) Sapindaceae. Ciência Agrotécnica, v.32, n.2, p.444-449, 2008. https://doi.org/10.1590/S1413$\underline{70542008000200015}$ 